\title{
Oxidação de braquetes metálicos
}

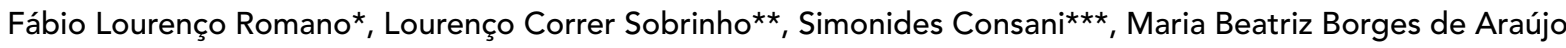

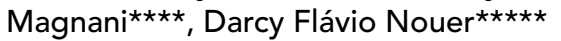

A colagem de braquetes diretamente ao esmalte dentário é um procedimento simples, que traz grandes vantagens estéticas ao paciente e benefícios ao profissional. Porém, deve-se usar técnica adequada e criteriosa, respeitando os passos indicados pelos fabricantes. Além disto, deve-se utilizar materiais de qualidade comprovada por pesquisas clínicas e laboratoriais. $\mathrm{Na}$ grande maioria das vezes a colagem do braquete é realizada com sucesso, entretanto, esta deve ser verificada durante todo o tratamento com a finalidade de evitar que defeitos na estrutura dos mesmos causem danos ao esmalte do paciente.

Não é raro observarmos algumas alterações como fraturas, aletas amassadas, separação da matha do restante do braquete, entre outros problemas, porém, cita-se em especial a oxidação da base do braquete (Fig. 1A, B). Quando na cavidade bucal o acessório não é capaz de resistir aos fluidos bucais, liberando substância de cor negra na superfície do esmalte.

Diante desta situação, o ortodontista deve

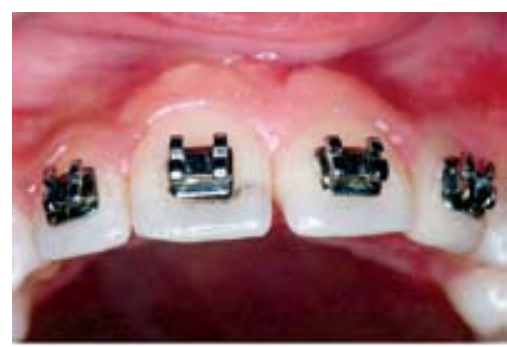

FIGURA 1A

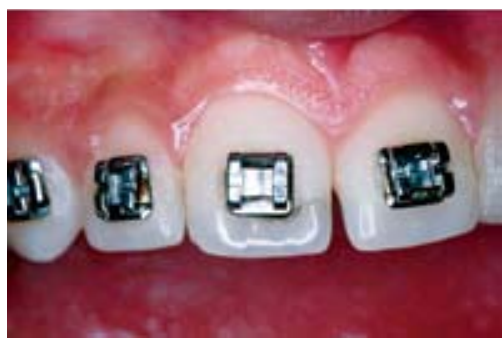

FIGURA 1B

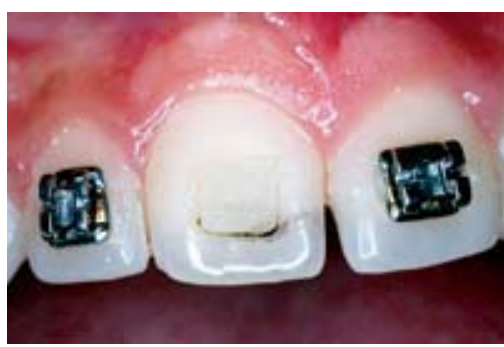

FIGURA 2

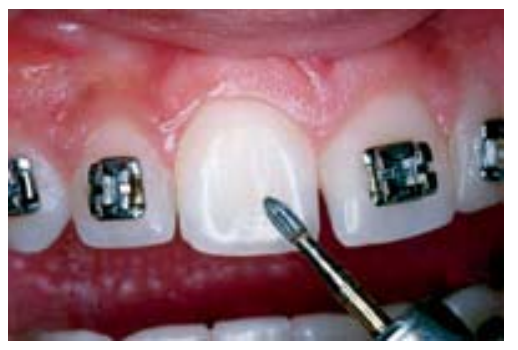

FIGURA 3

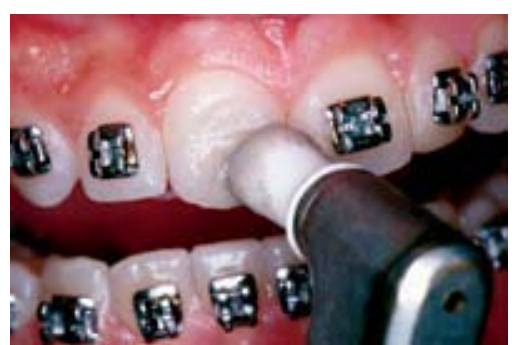

FIGURA 4

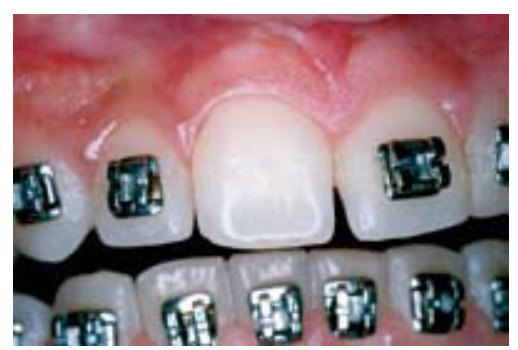

FIGURA 5

* Mestre em Ortodontia pela Faculdade de Odontologia de Piracicaba / UNICAMP. Professor do Curso de Especialização em Ortodontia - Efoa / Ceufe.

** Professor Titular da área de Materiais Dentários - Departamento de Odontologia Restauradora da Faculdade de Odontologia de Piracicaba - UNICAMP

*** Professor Titular da área de Materiais Dentários - Departamento de Odontologia Restauradora da Faculdade de Odontologia de Piracicaba - UNICAMP.

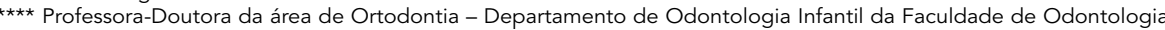
de Piracicaba - UNICAMP.

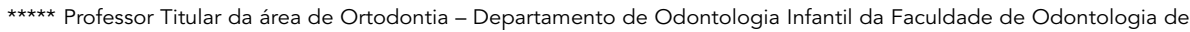
Piracicaba - UNICAMP. 


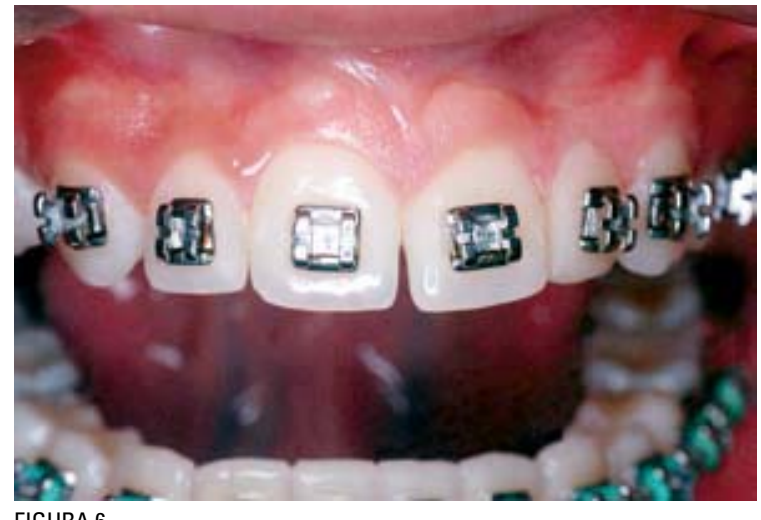

FIGURA 6

tomar providências imediatas para evitar que os produtos da oxidação penetrem na estrutura do esmalte e conseqüentemente provoquem manchas. Desta forma, o braquete deve ser removido com alicates próprios para este fim (How ou Weingart). Após a remoção do acessório o remanescente resinoso pigmentado pela oxidação (Fig. 2), deve ser removido com broca de carboneto de tungstênio (carbide) de 6 ou 12 lâminas (Fig. 3) em motor de baixa rotação somente atu-

\section{REFERÊNCIAS}

1. BELTRAMI, L. E. R.; FREITAS, C. A.; MARTINS, D. R. Bráquetes com sulcos retentivos na base, colados clinicamente e removidos em laboratório por testes de tração, cisalhamento e torção. Ortodontia, São Paulo, v. 29, n. 2, p. 27-39, maio/jun. 1996.

2. MIZRAHI, E. Surface distribution of enamel opacities following orthodontic treatment. Am J Orthod, St. Louis, v. 83, n. 5, p. 323-331, May 1983.

3. MORAES, H. T. Remoção de bráquetes colados. Rev Assoc Paul Cir Dent, São Paulo, v. 51, n. 1, p. 37-40, jan./fev. 1997.

4. RUELA, A. C. O et al. Efeitos sobre a topografia do esmalte de dois métodos de descolagem de bráquetes metálicos (in vivo). Rev CROMG, Belo Horizonte, v. 3, n. 1, p. 1-5, jan./jun. 1997.

5. ZACHRISSON BU. Bonding in Orthodontic. In: GRABER, T.M. SWAIN, B.F. Orthodontic current principle and technique. 1. ed., St. Louis, CV Mosby CO, 1985, 485p. ando com a broca sobre o compósito. Finalmente após remoção de todo compósito remanescente sobre o esmalte, realiza-se profilaxia da superfície vestibular com pasta de pedra-pomes e água com taça de borracha por aproximadamente 15 segundos (Fig. 4), lavagem e secagem pelo mesmo período de tempo. Com tais procedimentos é possível devolver a morfologia normal do esmalte dental (Fig. 5). Em seguida realiza-se colagem de outro bráquete seguindo os passos convencionais do procedimento para continuação da mecanoterapia ortodôntica (Fig. 6).

Se a oxidação não for detectada precocemente pode ocorrer pigmentação definitiva da estrutura do esmalte pela penetração dos produtos derivados da oxidação nos prismas de esmalte, causando aparência estética desfavorável ao paciente e podendo provocar dúvidas em relação ao material utilizado pelo ortodontista. Quando isto ocorre, o tratamento indicado é a remoção do braquete e do remanescente resinoso e em seguida restauração da área comprometida com compósito.
Endereço para correspondência

Fábio Lourenço Romano

Avenida do Café, 131 Bloco E Apto 16 - Vila Amélia

CEP: 14050-230 - Ribeirão Preto/SP

E-mail: flromano@aol.com 